\title{
Structure of a Rhamnogalacturonan Fragment from Apple Pectin: Implications for Pectin Architecture
}

\author{
Xiangmei Wu and Andrew Mort \\ Department of Biochemistry and Molecular Biology, Oklahoma State University, Stillwater, OK 74078-3035, USA \\ Correspondence should be addressed to Andrew Mort; andrew.mort@okstate.edu
}

Received 21 July 2014; Revised 15 October 2014; Accepted 25 October 2014; Published 14 December 2014

Academic Editor: John F. Kennedy

Copyright (C) 2014 X. Wu and A. Mort. This is an open access article distributed under the Creative Commons Attribution License, which permits unrestricted use, distribution, and reproduction in any medium, provided the original work is properly cited.

\begin{abstract}
A commercial apple pectin was sequentially digested with the cloned enzymes endopolygalacturonase, galactanase, arabinofuranosidase, xylogalacturonase, and rhamnogalacturonan hydrolase. The rhamnogalacturonan hydrolase-generated oligosaccharides were separated by ultrafiltration, anion exchange, and size-exclusion chromatography. Fractions from the ion exchange chromatography were pooled, lyophilized, and screened by MALDI-TOF MS. An oligosaccharide (RGP14P3) was identified and its structure, $\alpha$-D-GalpA-(1 $\rightarrow$ 2)- $\alpha$-L-Rhap- $(1 \rightarrow 4)-\alpha$-D-GalpA-(1 $\rightarrow$ 2)- $\alpha$-L-Rhap-(1 $\rightarrow 4)-\alpha$-D-GalpA, determined by $1 \mathrm{D}$ and 2D NMR spectrometry. This oligosaccharide probably represents a direct connection between homogalacturonan and rhamnogalacturonan in pectin. Alternatively, it could indicate that the nonreducing end of rhamnogalacturonan starts with a galacturonic acid residue.
\end{abstract}

\section{Introduction}

Pectin is probably the most complex macromolecule in nature, being composed of as many as 17 different monosaccharides $[1,2]$. These monosaccharides are organized in a number of distinct structural regions. The backbones of these regions fall into two groups: those containing 1,4-linked $\alpha$ $\mathrm{D}-\mathrm{Gal} p \mathrm{~A}$ residues (galacturonans) and those made up of a repeating disaccharide unit $[\rightarrow 2)-\alpha$-L-Rha $p-(1 \rightarrow 4)-\alpha$ $\mathrm{D}-\mathrm{Gal} p \mathrm{~A}-(1 \rightarrow]_{n}(\mathrm{RG}-\mathrm{I})$. Three classes of galacturonans are recognized: the unsubstituted homogalacturonan (HG), short stretches of galacturonan with closely spaced complex and simple side chains, rhamnogalacturonan II (RG-II), and xylogalacturonan (XGA) consisting of an HG backbone with multiple side branches of xylose linked to O-3 of the GalA residues.

Until recently structural models have depicted pectin as HG (smooth regions) and RG (hairy regions) forming one continuous backbone $[3,4]$. Recently, a model of pectin was suggested in which HG and XGA are depicted as side chains of RG $[2,5]$ and Yapo [4] suggested a model which is a hybrid of the two. Round et al. [6] found by atomic force microscopy coupled with mild acid hydrolysis that much of the HG extracted from green tomato fruit with sodium carbonate was devoid of any link to RG-I. The RG-I was all associated with high molecular weight complexes possibly covalently linked to additional $\mathrm{HG}$.

In this paper, we describe the purification and structural characterization of an oligosaccharide (RGP14P6), which supports the linear model for the way that HG and RG are connected together in apple pectin. Its structure was determined by MALDI-TOF MS and TOCSY, NOESY, HMQC, and $\mathrm{HMBC}$ NMR spectroscopy. As a connection between HG and RG-I, the oligosaccharide supports the model of HG and RG-I forming one continuous backbone.

\section{Materials and Methods}

2.1. Preparation of Rhamnogalacturonan Oligomers. Pectin from apple was purchased from Sigma-Aldrich Co. (SigmaAldrich, P8471. Lot 098K0181). Endopolygalacturonase, arabinofuranosidase, galactanase, xylogalacturonase, and rhamnogalacturonan hydrolase were cloned from $A$. nidulans. Xylogalacturonase was cloned from A. fumigatus, and all enzymes were expressed in P. pastoris [7]. Enzyme activities (units $/ \mathrm{mL}$ ) were assayed using a spectrophotometric method [8] modified as described previously [9]. Four $\mu \mathrm{L}$ substrate, $1 \mu \mathrm{L}$ enzyme, and $4 \mu \mathrm{L}$ buffer were mixed together and incubated at $37^{\circ} \mathrm{C}$. After $30 \mathrm{~min} 100 \mu \mathrm{L} 0.1 \mathrm{M}$ borate buffer, $\mathrm{pH} 9.0,50 \mu \mathrm{L} 1 \%$ 2-cyanoacetamide, and $40 \mu \mathrm{L}$ water were 


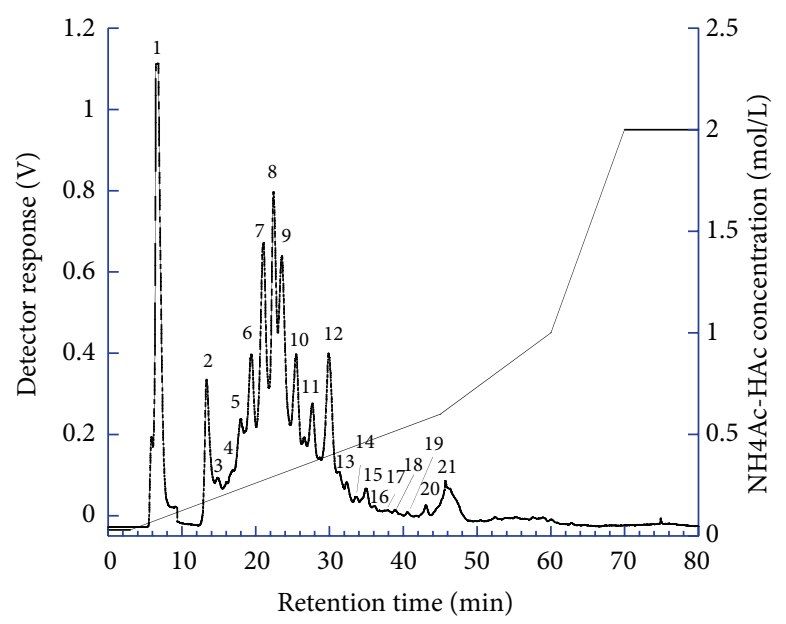

FIGURE 1: Evaporative light scattering profile of LW on anion-exchanged chromatography. The major components in each peak 2-21 were identified as oligomers with the following molecular formulas by MALDI-TOF MS: (1) not identified; (2) Rha $\mathrm{GalA}_{2} \mathrm{Gal}_{4} \mathrm{Ara}$; (3) Rha $\mathrm{GalA}_{2} \mathrm{Gal}_{4}$; (4) $\mathrm{Rha}_{2} \mathrm{GalA}_{2} \mathrm{Gal}_{3}, \mathrm{Rha}_{2} \mathrm{GalA}_{2} \mathrm{Gal}_{2}$; (5) $\mathrm{Rha}_{2} \mathrm{GalA}_{2} \mathrm{Gal}_{2}$; (6) Rha $\mathrm{GalA}_{2} \mathrm{GalAra}$; (7) Rha $\mathrm{GalA}_{2} \mathrm{Gal}_{2}$ (8) $\mathrm{Rha}_{2} \mathrm{GalA}_{2}$; (9) Rha $\mathrm{RalA}_{2} \mathrm{Gal}_{2}$,


$\mathrm{Rha}_{3} \mathrm{GalA}_{3}$, Rha GalA $_{2}$ AcetylGalAGal, Rha GalAAcetylGalA $_{2}$; (13) Rha $\mathrm{RalA}_{2}$ AcetylGalA, Rha $\mathrm{GalA}_{3}, \mathrm{Rha}_{4} \mathrm{GalA}_{3}$ AcetylGalA, Rha $_{4} \mathrm{GalA}_{4}$; (14) $\mathrm{Rha}_{2} \mathrm{GalA}_{3}$, Rha $\mathrm{GalA}_{3}$ AcetylGalA; (15) $\mathrm{Rha}_{4} \mathrm{GalA}_{3}$ AcetylGalA, Rha $\mathrm{GalA}_{3}$; (16) Rha $\mathrm{GalA}_{3} \mathrm{AcetylGalA}_{4} \mathrm{Rha}_{4} \mathrm{GalA}_{2} \mathrm{AcetylGalA}_{2}$, $\mathrm{Rha}_{2} \mathrm{GalA}_{3}$; (17) Rha $\mathrm{GalA}_{4}$, Rha AcetylGalA $_{4}$; (18) Rha $\mathrm{R}_{2}$ AcetylGalA 4 , Rha $\mathrm{GalA}_{4}$, Rha $\mathrm{GalA}_{4}$ MethylGalA; (19) Rha GalA $\mathrm{MethylGalA}_{2}$ (20) $\mathrm{GalA}_{2} ;(21) \mathrm{GalA}_{3}$. The order of fragments in each peak is given according to their intensity in the MALDI-TOF MS spectrum.

added and the mixture was heated in a boiling water bath for $10 \mathrm{~min}$. After the reaction mixture cooled, the absorbance at $276 \mathrm{~nm}$ was measured on a NanoDrop ND-1000 spectrometer (NanoDrop Technology, DE).

Pectin $(20 \mathrm{~g})$ was suspended in $30 \mathrm{~mL}$ of acetone; then $700 \mathrm{~mL}$ water was added with vigorous stirring. The suspension was adjusted to $\mathrm{pH} 4.0$ with $1 \mathrm{M} \mathrm{NaOH}$ and $1 \mathrm{~mL}$ (50 units) of endopolygalacturonase (EPG, AN 8327.2) added. After incubation for $72 \mathrm{hrs}$ at $37^{\circ} \mathrm{C}$ followed by centrifugation, the solution was collected and subjected to ultrafiltration using a 10,000 MWT cutoff membrane. The solution remaining inside the ultrafiltration unit was diluted with deionized water and adjusted to $\mathrm{pH} 11$ with $1 \mathrm{M} \mathrm{NaOH}$ until the $\mathrm{pH}$ stopped changing. A small amount of $\beta$-elimination of GalA residues could take place at this step. After adjusting the $\mathrm{pH}$ back to 4.0, the solution was again digested with EPG. The ultrafiltration retentate was then sequentially digested for $72 \mathrm{hrs}$ at $37^{\circ} \mathrm{C}$ with arabinosidase (AN1571.2), galactanase (AN5727.2), xylogalacturonase (Afu8g06890), and rhamnogalacturonan hydrolase (AN9314.2), at pH 4.0 for endopolygalacturonase and rhamnogalacturonan hydrolase and $\mathrm{pH}$ 5.0 for the other enzymes [7]. An estimated fourfold excess of enzyme activity (four times the number of units needed to digest the substrate in 72 hours) was added to ensure complete digestion.

For testing the progress of the digestions $2 \mu \mathrm{L}$ aliquots were taken, labeled with 8-aminonaphthalene-1,3,6-trisulfonic acid (ANTS), and analyzed by capillary zone electrophoresis (CZE). The digestion was deemed complete when the pattern of peaks stopped changing.

2.2. Liquid Chromatography. The ultrafiltrate from the rhamnogalacturonan hydrolase digestion was freeze-dried. This low molecular weight fraction (LMW) was separated on an anion-exchanged column $(22 \times 250 \mathrm{~mm}$, CarboPac PA1, Dionex, CA). The column was eluted with a gradient of ammonium acetate buffer $(\mathrm{pH} 5.2)$ at a flow rate of $5.0 \mathrm{~mL} / \mathrm{min}$ and the sugar content was monitored by an evaporative light scattering detector with the eluate split $1: 25$ between the detector and the fraction collector. Fractions were collected every min. The elution profile is shown in Figure 1. The fractions corresponding to the numbered peaks were pooled and lyophilized.

Fraction P14 was separated further on a Superdex peptide column $(10 \times 300 \mathrm{~mm}$, Tricorn, Sweden $)$. The column was equilibrated and eluted with $200 \mathrm{mM}$ ammonium acetate buffer ( $\mathrm{pH}$ 5.2) at a flow rate of $0.3 \mathrm{~mL} / \mathrm{min}$. The sugar content was monitored by a refractive index detector (Shodex RI17, Japan). Fractions were collected every min. The elution pattern is shown in Figure 2. Fractions were collected as indicated in $20 \mathrm{~mL}$ vials and freeze-dried four times to remove ammonium acetate completely before MALDI-TOF MS and NMR analyses.

2.3. Gas Liquid Chromatography (GLC) Sugar Composition Analysis and Capillary Zone Electrophoresis (CZE). Sugar compositions were determined by GLC analysis of the trimethylsilyl methyl glycosides. Methanolysis and derivatization were performed using the protocol of Chaplin [10] modified by Komalavilas and Mort [11].

Oligosaccharides were reductively aminated with ANTS for analysis by CZE. The CZE was performed as described previously on a custom built instrument [12].

2.4. Matrix-Assisted Laser Desorption Time-of-Flight Mass Spectrometry (MALDI-TOF-MS). Samples, $0.25 \mu \mathrm{L}$ ( 10 mg/ $\mathrm{mL}$ in $\mathrm{H}_{2} \mathrm{O}$ ), were spotted on top of $0.25 \mu \mathrm{L}$ matrix 


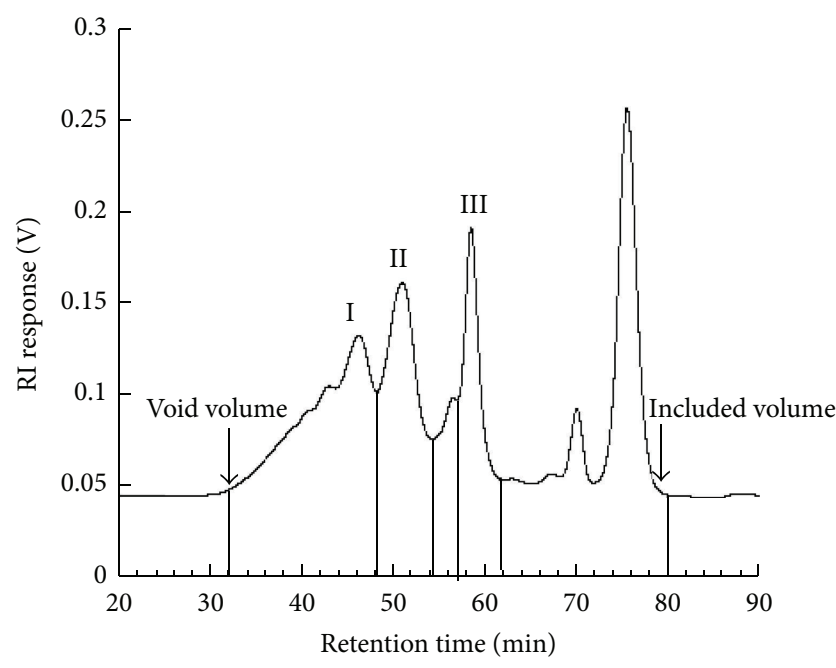

FIGURE 2: Superdex size-exclusion chromatography profile of fraction 14 pooled from the anion-exchanged column. Void volume and included volume were at 32 and 75 mins. The peak labeled by III is oligomer RGP14P3.

(100 mg/mL 2,4,6-trihydroxyacetophenone in $\mathrm{MeOH}$ ) on $96 \times 2$ sample plates and dried in air. Spectra were obtained on a Perseptive Biosystems Voyager DE PRO matrix-assisted laser desorption time-of-flight mass spectrometer in the negative ion reflector mode.

2.5. Nuclear Magnetic Resonance (NMR) Spectroscopy. ${ }^{1} \mathrm{H}-$ NMR and TOCSY, COSY, HMBC, HMQC, and NOESY spectra were recorded at $21^{\circ} \mathrm{C}$ on a Varian Unity Inova 600 NMR spectrometer using Varian VNMRJ software. Samples were dissolved in $99.9 \% \mathrm{D}_{2} \mathrm{O}$ (Sigma-Aldrich, MO). Proton decoupled ${ }^{13} \mathrm{C}-\mathrm{NMR}$ spectra (HMQC and $\mathrm{HMBC}$ ) were recorded using a Varian $5 \mathrm{~mm} \mathrm{CHN}$ triple resonance probe at $150.82 \mathrm{MHz}$. Total correlation spectroscopy (TOCSY) experiments were performed with a mixing time of $100 \mathrm{~ms}$. All spectra used presaturation mode to suppress the water peak with saturation power at -9 .

\section{Results and Discussion}

Apple pectin (20 g) was digested with endopolygalacturonase (EPG) and then ultrafiltered to remove the bulk of the HG fragments. The retentate was then saponified with $0.1 \mathrm{M}$ $\mathrm{NaOH}$ ( $\mathrm{pH} 11$ ) to make the remaining HG susceptible to EPG digestion. After sequential digestion with arabinofuranosidase to remove arabinose side chains from the galactan and arabinan, galactanase to remove the galactan, and xylogalacturonase to degrade the xylogalacturonan, low molecular weight products (less than 10,000 MW) were removed by ultrafiltration. A significant amount of the low molecular weight EPG digestion products may not have been removed because of their anomalous size behavior [13]. Unfortunately our Pichia clones of endoarabinanase and $\beta$ galactosidase do not produce adequate amounts of enzyme to be useful [7]. The high molecular weight products (more than 10,000 MW) were finally treated with rhamnogalacturonan hydrolase
TABLE 1: Carbohydrate composition of fractions.

\begin{tabular}{lccccccc}
\hline \multirow{2}{*}{ Fraction } & \multicolumn{6}{c}{ Monosaccharide composition (mol\%) } \\
& Ara & Rha & Xyl & GalA & Man & Gal & Glc \\
\hline Pectin & 2.7 & 6.1 & 2.4 & 76.3 & 0.1 & 8.8 & 3.6 \\
HW & 3.1 & 4.6 & 16.1 & 30.7 & 7.8 & 8.5 & 29.1 \\
LW & 8.9 & 24.1 & 4.4 & 40.1 & 1.7 & 16.9 & 2.4 \\
P14 & 3.6 & 33.3 & 9.7 & 40.9 & & 10 & 2.5 \\
RGP14P3 & & 36.1 & Trace & 57.6 & \multicolumn{5}{c}{ Trace } \\
\hline
\end{tabular}

(RGase). RGase cuts RG between GalA and Rha residues producing oligomers with Rha at their nonreducing end [14, 15]. Progress of the hydrolysis was monitored by changes in the oligosaccharide product distribution seen by CZE of aliquots labeled with ANTS [16].

After ultrafiltration of the RGase digest, $930 \mathrm{mg}$ of low molecular weight products (LW) and $1403 \mathrm{mg}$ of high molecular weight products (HW) were obtained. The sugar compositions of the various fractions are shown in Table 1. The starting pectin had a high proportion of GalA followed by $\mathrm{Gal}$ and Rha, presumably reflecting extensive HG regions along with lesser amounts of RG with predominantly galactan side chains. From its sugar composition the HW fraction appeared to be a combination of XGA, highly branched $\mathrm{RG}$, and starch, a known contaminant in commercial pectin preparations. The LW had more equal proportions of Rha, GalA, and Gal residues, which is consistent with it containing predominantly the $(\mathrm{RG})_{2}$ and $(\mathrm{RG})_{3}$ oligomers, with or without single Gal side chains, that have been reported previously to be the major products from RGase digestion of modified hairy regions of apple pectin $[14,15]$. A portion of the LW fraction (114 mg) was separated on an anion-exchange column (Carbopac PA1) using a gradient of ammonium acetate buffer as eluent. Twenty-one peaks appeared between $0.03 \mathrm{M}$ and $1 \mathrm{M}$ ammonium acetate and were collected as fractions P1-P21, as shown in Figure 1. Fractions were analyzed by MALDI-TOF MS. Knowing that only GalA, Rha, Gal, and Ara were the major sugars present we could deduce the sugar composition of the oligomers from their masses. The major oligomers contained equal numbers of GalA and Rha residues, as expected for the products of digestion of RG by RGase [14]. However, there were small amounts of oligomers containing more GalA than Rha in peaks 9 and 14-19. These oligomers were thought likely to represent junctions between HG and RG. An oligomer in peak 9 contained more Rha than GalA. The potential origin of this oligomer will be the subject of a future report.

The mixture of oligomers in fraction P14 was separated on a Superdex peptide column to give three major sugar containing peaks with retention times of 46, 51, and 59 min which were collected as fractions I, II, and III, respectively, as shown in Figure 2. We named peak III RGP14P3.

The MALDI-TOF-MS spectrum of the oligomer (see Figure 3) had major ions at $m / z 837.33$ and 859.31 which correspond to $\left[\mathrm{Rha}_{2} \mathrm{GalA}_{3}-\mathrm{H}\right]^{-}$and $\left[\mathrm{Rha}_{2} \mathrm{GalA}_{3}-2 \mathrm{H}+\mathrm{Na}\right]^{-}$, respectively. Compositional analysis indicated that the RGP14P3 fraction contained Rha and GalA in a molar ratio of $1: 1.42$. The ${ }^{1} \mathrm{H}-\mathrm{NMR}$ spectra of RGP14P3 were obtained 


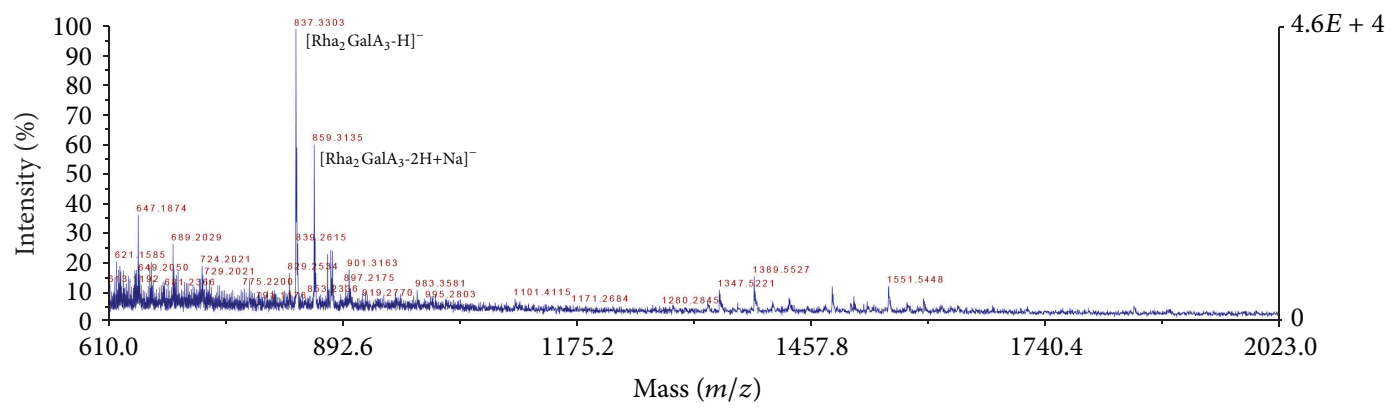

Figure 3: The MALDI-TOF-MS spectrum of P14. The major ions peaks at $m / z 837.33$ and 859.31 correspond to $\left[\mathrm{Rha}_{2} \mathrm{GalA}_{3}-\mathrm{H}\right]^{-}$and $\left[\mathrm{Rha}_{2} \mathrm{GalA}_{3}-2 \mathrm{H}+\mathrm{Na}\right]^{-}$, respectively.

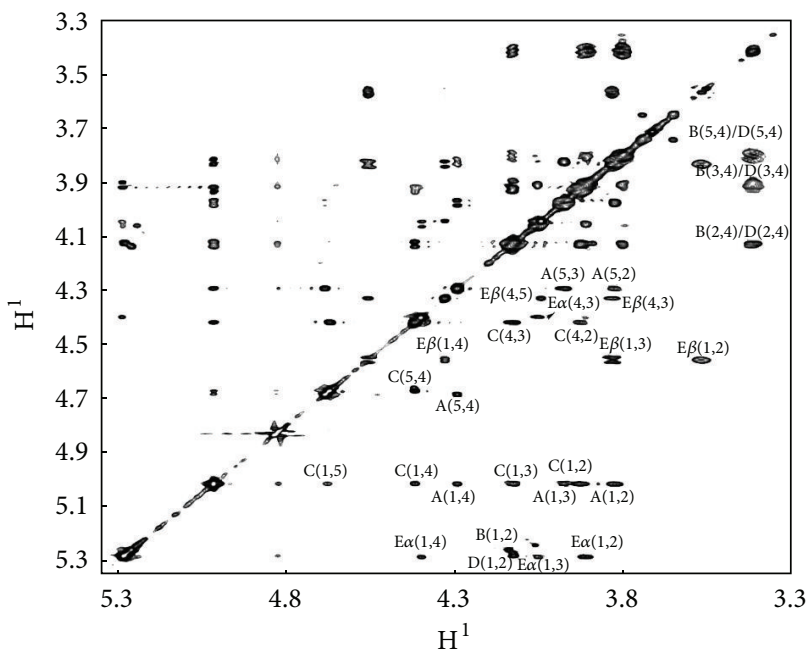

FIGURE 4: TOCSY spectrum of RGP14P3. A, terminal $\alpha$-galacturonic acid; $\mathrm{B}$, internal rhamnose; $\mathrm{C}$, internal galacturonic acid; $\mathrm{D}$, internal rhamnose; $\mathrm{E} \alpha$, reducing end $\alpha$-galacturonic acid; $\mathrm{E} \beta$, reducing end $\beta$-galacturonic acid.

and compared to the spectra obtained by Schols et al. for simple RG oligomers [15]. The ${ }^{1} \mathrm{H}$ chemical shifts of signals from the methyl groups of rhamnopyranose in RG oligomers appear to be diagnostic of the environment of the rhamnose. If the rhamnose is at the nonreducing terminus and does not have a substituent on $\mathrm{O}-4$, the signal appears at $1.23 \mathrm{ppm}$. If it is internal with no branch it is at $1.24 \mathrm{ppm}$. Rhamnose with a branch at the terminus gives a signal at 1.29 and the internal one at $1.31 \mathrm{ppm}$ [14]. In the ${ }^{1} \mathrm{H}-\mathrm{NMR}$ of peak III, there was only one doublet centered around $1.24 \mathrm{ppm}$ indicating that both rhamnoses were unbranched and internal in the oligomer. A signal at $4.28 \mathrm{ppm}$ characteristic of $\mathrm{H}-4$ of a nonreducing terminal GalA was clearly present in the ${ }^{1} \mathrm{H}-\mathrm{NMR}$ spectra of RGP14P3 [17].

In the TOCSY spectrum (Figure 4), four sets of correlations to galacturonic acid anomeric protons can be seen. The anomeric protons of the $\alpha$ and $\beta$ reducing end GalA at 4.55 and 5.28 ppm correlated with $\mathrm{H}-4$ signals at 4.39 and $4.33 \mathrm{ppm}$, respectively, indicating that a sugar, most likely Rha, was linked to it through O-4. At $5.01 \mathrm{ppm}$, there was an overlapping set of two correlations: one with an $\mathrm{H}-4$ signal at $4.41 \mathrm{ppm}$, indicating a 4-linked GalA, and the other with $\mathrm{H}-4$ at $4.28 \mathrm{ppm}$, suggesting a terminal GalA. Two very closely spaced signals for the anomeric protons of Rha at 5.24 and $5.26 \mathrm{ppm}$ were correlated to $\mathrm{H}-2$ at 4.12 and $4.11 \mathrm{ppm}$, respectively.

Five anomeric signals were found in the HMQC spectrum (Figure 5). They were assigned to be from the $\alpha$ and $\beta$ reducing end GalA at C-1/H-1, 93.0/5.28 ppm and 96.96/4.55 ppm, from an internal $\alpha$-GalA superimposed on one from a terminal GalA at $98.26 / 5.01 \mathrm{ppm}$, and two closely spaced signals from internal $\alpha$-Rha residues at 99.25/5.24 ppm and $99.25 / 5.26 \mathrm{ppm}$. From the information provided by the TOCSY, HMQC, and HMBC spectra, along with literature reports, we could assign all of the carbon and proton chemical shifts of the oligosaccharide (see Table 2). In the HMBC spectrum (Figure 6) we can see multiple-bond correlations showing the linkages between the sugars. The correlations $\mathrm{BC}(1,4), \mathrm{DE} \alpha(1,4), \mathrm{DE} \beta(1,4), \mathrm{E} \beta \mathrm{D}(4,1), \mathrm{E} \alpha \mathrm{D}(4,1)$, and $\mathrm{CB}(4,1)$ show that both Rha residues are attached (1-4) to the following GalA residue in the chain. Correlations $\mathrm{BA}(2,1), \mathrm{DC}(2,1)$, $\mathrm{AB}(1,2)$, and $\mathrm{CD}(1,2)$ show that GalA residues $\mathrm{A}$ and $\mathrm{C}$ are both linked- $(1 \rightarrow 2)$ to the following Rha residue. Based on all of the results described above, the structure of RGP14P3 was

$$
\begin{array}{ccccc}
\mathrm{A} & \mathrm{B} & \mathrm{C} & \mathrm{D} & \mathrm{E} \\
\alpha \text {-D-GalpA- }(1 \rightarrow 2)-\alpha-\mathrm{L}-\mathrm{Rha} p-(1 \rightarrow 4)-\alpha-\mathrm{D}-\mathrm{Gal} p \mathrm{~A}-(1 \rightarrow 2)-\alpha \text {-L-Rha } p-(1 \rightarrow 4)-\alpha \text { or }-\mathrm{D}-\mathrm{Gal} p \mathrm{~A}
\end{array}
$$

Rhamnogalacturonan oligomers with the same structure have most likely been generated before, in two different ways. Mutter et al. treated $(\mathrm{RG})_{3}$ with RG-rhamnohydrolase to remove the nonreducing terminal Rha thus generating
GRGRG [17] and Sengkhamparn et al. [18] saw peaks corresponding to GRGRG in the MALDI-TOF MS spectra of their RGase digest of okra pectin. Hence, the authors concluded that they were $(\mathrm{RG})_{n}$ oligomers with their terminal Rha 
TABLE 2: Assignments of chemical shifts of RGP14P3.

\begin{tabular}{lcccccc}
\hline & C-1/H-1 & C-2/H-2 & C-3/H-3 & C-4/H-4 & C-5/H-5 & C-6/H-6 \\
\hline$\rightarrow$ 4)- $\alpha$-D-GalpA & $93.0 / 5.28$ & $68.72 / 3.92$ & $71.11 / 4.05$ & $78.17 / 4.39$ & $71.44 / 4.40$ & 176.4 \\
$\rightarrow$ 4)- $\beta$-D-GalpA & $96.96 / 4.55$ & $72.41 / 3.51$ & $74.55 / 3.83$ & $77.53 / 4.33$ & $75.39 / 4.04$ & 175.8 \\
$\rightarrow$ 4)- $\alpha$-D-GalpA-(1 $\rightarrow$ & $98.26 / 5.01$ & $70.08 / 3.91$ & $70.98 / 4.13$ & $78.04 / 4.41$ & $72.15 / 4.67$ & 176.2 \\
$\alpha$-D-GalpA-(1 $\rightarrow$ & $98.26 / 5.01$ & $74.61 / 3.83$ & $70.14 / 3.98$ & $71.57 / 4.28$ & $72.86 / 4.68$ & 176.3 \\
$\rightarrow$ 2)- $\alpha$-L-RhapA-(1 $\rightarrow$ & $99.25 / 5.24$ & $76.87 / 4.12$ & $68.72 / 3.82$ & $72.73 / 3.40$ & $69.82 / 3.80$ & $17.4 / 1.25$ \\
$\rightarrow$ 2)- $\alpha$-L-RhapA-(1 $\rightarrow$ & $99.25 / 5.26$ & $76.87 / 4.11$ & $68.72 / 3.82$ & $72.73 / 3.40$ & $69.82 / 3.80$ & $17.4 / 1.25$ \\
\hline
\end{tabular}

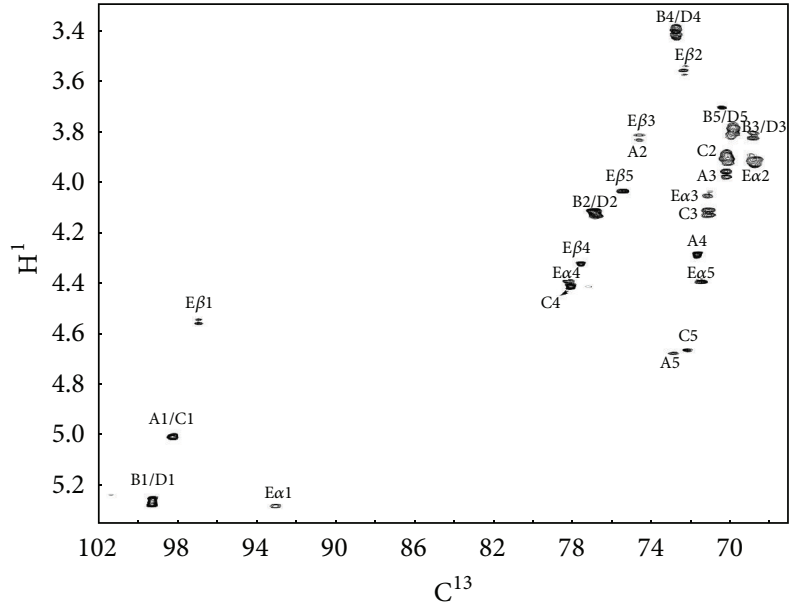

FIGURE 5: HMQC spectrum of RGP14P3. Symbols in the spectrum represent the different glycosyl residues as described in Figure 3.

residues removed by RG-rhamnohydrolase contaminating their RGase. (A batch of endogalactanase which we obtained from Megazyme showed significant RG-rhamnohydrolase activity.) Coenen et al. [19] generated a series of oligomers from apple modified hairy regions by partial acid hydrolysis. The authors observed through MALDI-TOF MS that one of them was characterized by a Rha to GalA ratio of $2 / 3$.

To be sure that our oligomer was not the result of contaminating RG-rhamnohydrolase, we tested each of the enzymes we used against an APTS labeled $(\mathrm{RG})_{3}$ oligomer using RGP14P3-APTS as a standard. Only the commercial galactosidase preparation from Megazyme (that we did not use in the preparation of the oligosaccharide) showed any conversion of the $(\mathrm{RG})_{3}$ oligomer to something migrating at the same rate as RGP14P3-APTS.

To explain the generation of the RGP14P3 we propose that the reducing end of the oligomer was generated by hydrolysis within the backbone of an RG segment, and the nonreducing end was generated by hydrolysis of HG by the endopolygalacturonase. We [16] and others $[20,21]$ have shown that EPG needs four adjacent GalA residues to act, and it cleaves between the third and fourth residue. Thus, it is quite reasonable to expect a single GalA residue from $\mathrm{HG}$ to be left attached to an RG oligomer. We have seen traces of oligomers containing two more GalA than Rha residues

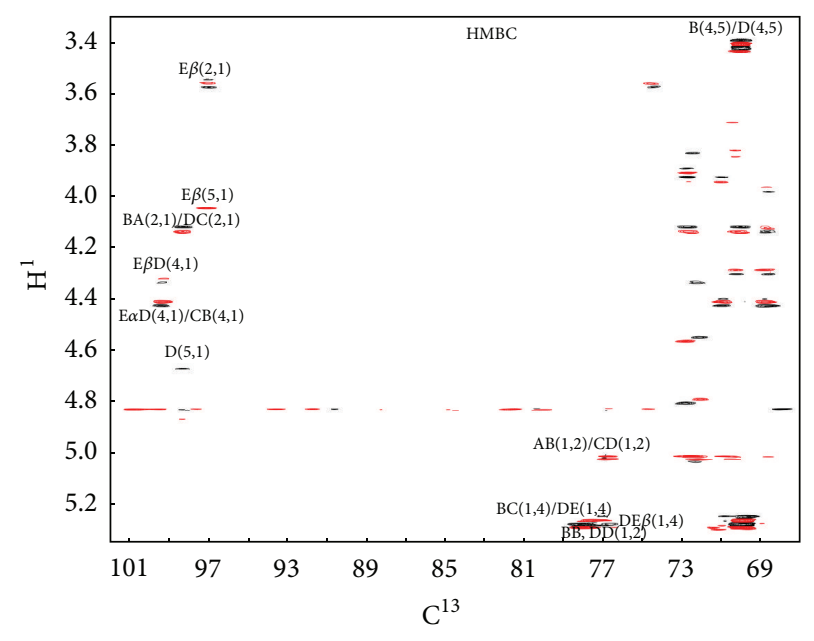

FIgURE 6: HMBC spectrum of RGP14P3. Symbols in the spectrum represent the different glycosyl residues as described in Figure 3. The first letter corresponds to the $\mathrm{H}^{1}$ chemical shift and the second to that of the $\mathrm{C}^{13}$. The first number corresponds to the $\mathrm{H}$-position and the second to the carbon.

by MALDI-TOF MS, but not in adequate quantities for full characterization by NMR.

From the structure of RGP14P6 we can deduce that HG and RG, at least in apple pectin, most probably, are covalently linked together through an $\alpha$-(1 $\rightarrow 2)$-linkage between the reducing terminal GalA of the $\mathrm{HG}$ and the nonreducing terminal Rha of RG. Coenen et al. [19] reached the same conclusion from their electrospray MSMS analysis of a partial acid hydrolysate of apple pectin modified hairy region. An alternate possibility is that the nonreducing end of RG starts with a GalA residue and thus naturally the oligomer produced from the nonreducing end of RG by RGase digestion would be the one we characterized.

\section{Conclusions}

An oligosaccharide was generated and purified from apple pectin using enzymes of defined specificity and fractionation by ion exchange and size-exclusion chromatography. The structure of the oligosaccharide is strongly supportive of the idea that HG is linked in a linear fashion to RG via an $\alpha$ $(1 \rightarrow 2)$ linkage to the Rha residue at the nonreducing end of RG. 


\section{Conflict of Interests}

The authors declare that there is no conflict of interests regarding the publication of this paper.

\section{Acknowledgments}

This work was funded by the Division of Chemical Sciences, Geosciences, and Biosciences, Office of Basic Energy Sciences of the U.S. Department of Energy, through Grant DE-FG0296ER20215 and it has been approved for publication by the Director of the Oklahoma Agricultural Experiment Station.

\section{References}

[1] B. L. Ridley, M. A. O’Neill, and D. Mohnen, "Pectins: structure, biosynthesis, and oligogalacturonide-related signaling," Phytochemistry, vol. 57, no. 6, pp. 929-967, 2001.

[2] J. P. Vincken, H. A. Schols, R. J. F. J. Oomen, G. Beldman, R. G. F. Visser, and A. G. J. Voragen, "Pectin-the hairy thing," in Advances in Pectin and Pectinase Research: The 2nd International Symposium on Pectins and Pectinases, Rotterdam, Netherlands, pp. 47-59, 2010.

[3] J. A. de Vries, F. M. Rombouts, A. G. J. Voragen, and W. Pilnik, "Enzymic degradation of apple pectins," Carbohydrate Polymers, vol. 2, no. 1, pp. 25-33, 1982.

[4] B. M. Yapo, "Pectic substances: From simple pectic polysaccharides to complex pectins-a new hypothetical model," Carbohydrate Polymers, vol. 86, no. 2, pp. 373-385, 2011.

[5] J.-P. Vincken, H. A. Schols, R. J. F. J. Oomen et al., "If homogalacturonan were a side chain of rhamnogalacturonan I. Implications for cell wall architecture," Plant Physiology, vol. 132, no. 4, pp. 1781-1789, 2003.

[6] A. N. Round, A. J. MacDougall, S. G. Ring, and V. J. Morris, "Unexpected branching in pectin observed by atomic force microscopy," Carbohydrate Research, vol. 303, no. 3, pp. 251-253, 1997.

[7] S. Bauer, P. Vasu, S. Persson, A. J. Mort, and C. R. Somerville, "Development and application of a suite of polysaccharidedegrading enzymes for analyzing plant cell walls," Proceedings of the National Academy of Sciences of the United States of America, vol. 103, no. 30, pp. 11417-11422, 2006.

[8] S. Honda, Y. Nishimura, M. Takahashi, H. Chiba, and K. Kakehi, "A manual method for the spectrophotometric determination of reducing carbohydrates with 2-cyanoacetamide," Analytical Biochemistry, vol. 119, no. 1, pp. 194-199, 1982.

[9] Y. Zheng and A. Mort, "Isolation and structural characterization of a novel oligosaccharide from the rhamnogalacturonan of Gossypium hirsutum L.," Carbohydrate Research, vol. 343, no. 6, pp. 1041-1049, 2008.

[10] M. F. Chaplin, "A rapid and sensitive method for the analysis of carbohydrate components in glycoproteins using gas-liquid chromatography," Analytical Biochemistry, vol. 123, no. 2, pp. 336-341, 1982.

[11] P. Komalavilas and A. J. Mort, "The acetylation of O-3 of galacturonic acid in the rhamnose-rich portion of pectins," Carbohydrate Research, vol. 189, pp. 261-272, 1989.

[12] J. M. Merz and A. J. Mort, "A computer-controlled variable light attenuator for protection and autoranging of a laser-induced fluorescence detector for capillary zone electrophoresis," Electrophoresis, vol. 19, no. 12, pp. 2239-2242, 1998.
[13] A. J. Mort, B. M. Moerschbacher, M. L. Pierce, and N. O. Maness, "Problems encountered during the extraction, purification, and chromatography of pectic fragments, and some solutions to them," Carbohydrate Research, vol. 215, no. 1, pp. 219-227, 1991.

[14] I. J. Colquhoun, G. A. de Ruiter, H. A. Schols, and A. G. J. Voragen, "Identification by n.m.r. spectroscopy of oligosaccharides obtained by treatment of the hairy regions of apple pectin with rhamnogalacturonase," Carbohydrate Research, vol. 206, no. 1, pp. 131-144, 1990.

[15] H. A. Schols, A. G. J. Voragen, and I. J. Colquhoun, "Isolation and characterization of rhamnogalacturonan oligomers, liberated during degradation of pectic hairy regions by rhamnogalacturonase," Carbohydrate Research, vol. 256, no. 1, pp. 97111, 1994.

[16] A. J. Mort and E. M. W. Chen, "Separation of 8-aminonaphthalene-1,3,6-trisulfonate (ANTS)-labeled oligomers containing galacturonic acid by capillary electrophoresis: application to determining the substrate specificity of endopolygalacturonases," Electrophoresis, vol. 17, no. 2, pp. 379-383, 1996.

[17] M. Mutter, C. M. G. C. Renard, G. Beldman, H. A. Schols, and A. G. J. Voragen, "Mode of action of RG-hydrolase and RGlyase toward rhamnogalacturonan oligomers. Characterization of degradation products using RG-rhamnohydrolase and RGgalacturonohydrolase," Carbohydrate Research, vol. 311, no. 3, pp. 155-164, 1998.

[18] N. Sengkhamparn, E. J. Bakx, R. Verhoef, H. A. Schols, T. Sajjaanantakul, and A. G. J. Voragen, "Okra pectin contains an unusual substitution of its rhamnosyl residues with acetyl and alpha-linked galactosyl groups," Carbohydrate Research, vol. 344, no. 14, pp. 1842-1851, 2009.

[19] G. J. Coenen, E. J. Bakx, R. P. Verhoef, H. A. Schols, and A. G. J. Voragen, "Identification of the connecting linkage between homo- or xylogalacturonan and rhamnogalacturonan type I," Carbohydrate Polymers, vol. 70, no. 2, pp. 224-235, 2007.

[20] L. Rexova-Benkova and O. Markovic, "Pectic enzymes," Advances in Carbohydrate Chemistry and Biochemistry, vol. 33, pp. 323-385, 1976.

[21] B. M. Yapo, P. Lerouge, J.-F. Thibault, and M.-C. Ralet, “Pectins from citrus peel cell walls contain homogalacturonans homogenous with respect to molar mass, rhamnogalacturonan I and rhamnogalacturonan II," Carbohydrate Polymers, vol. 69, no. 3, pp. 426-435, 2007. 

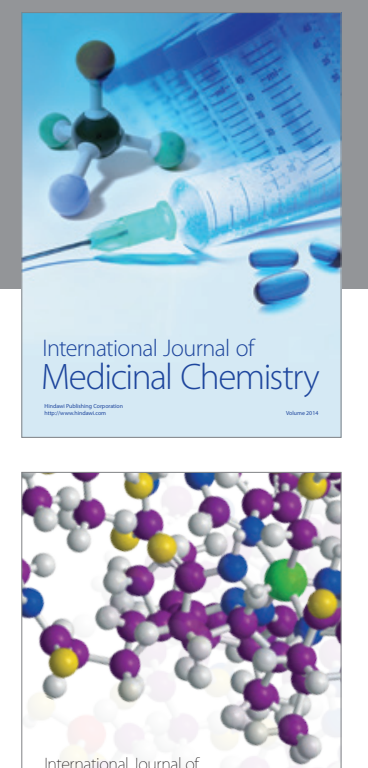

\section{Carbohydrate} Chemistry

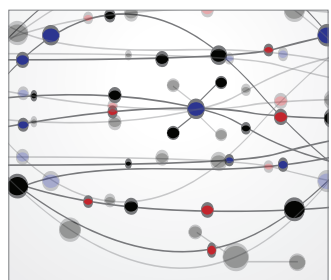

The Scientific World Journal
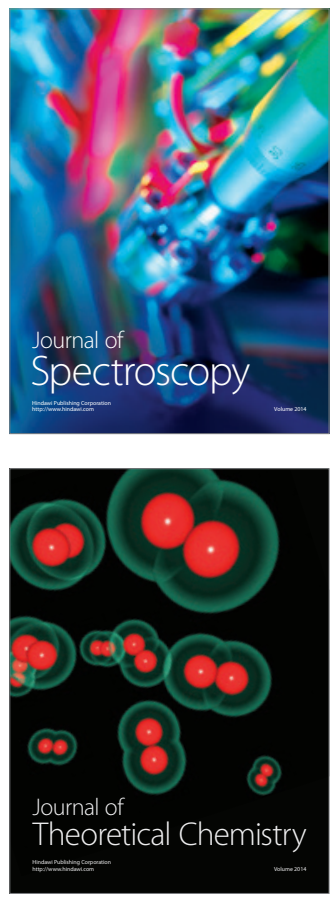
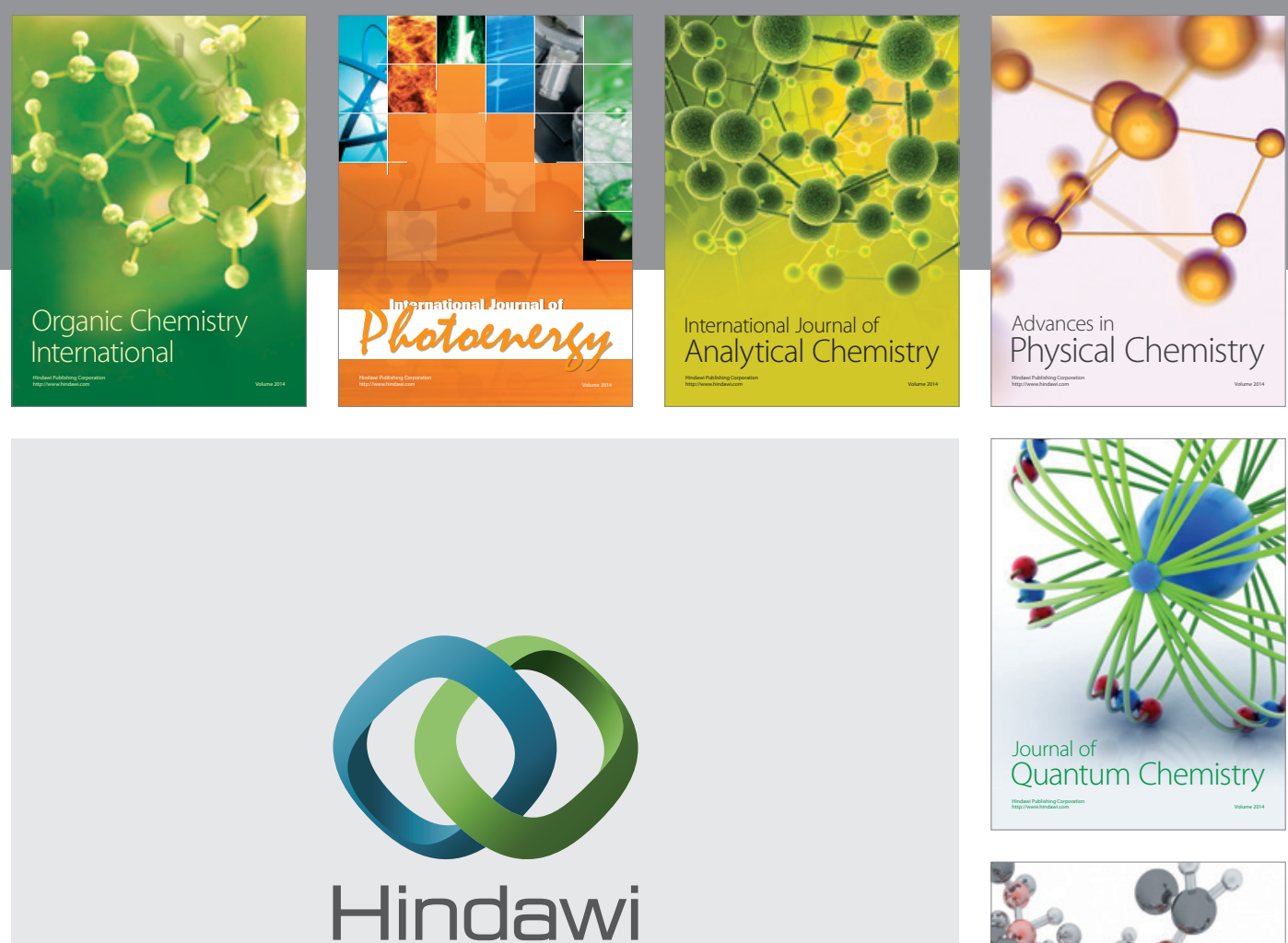

Submit your manuscripts at

http://www.hindawi.com

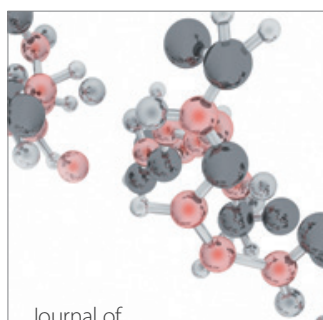

Analytical Methods

in Chemistry

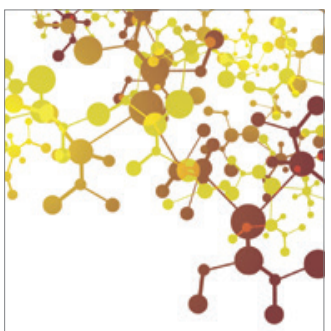

Journal of

Applied Chemistry

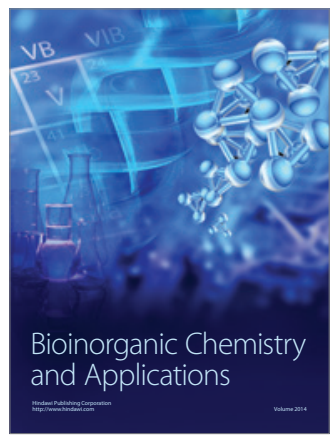

Inorganic Chemistry
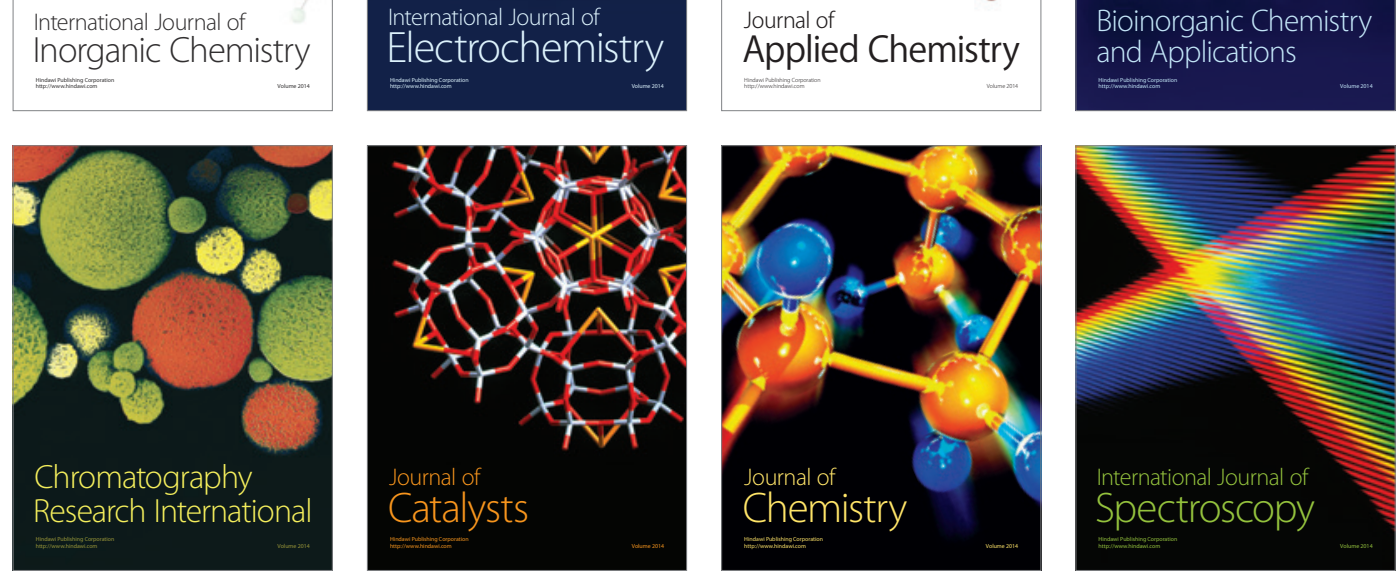